\title{
Medioambiente, conflictos socioambientales y derechos humanos
}

\section{Introducción}

Hasta 2016 el Instituto Nacional de Derechos Humanos (INDH) había identificado más de cien conflictos socioambientales en Chile, definiéndolos como «disputas entre diversos actores - personas naturales, organizaciones, empresas públicas y privadas, y el Estado-, manifestadas públicamente y que expresan divergencias de opiniones, posiciones, intereses y planteamientos de demandas por la afectación (o potencial afectación) de derechos humanos, derivada del acceso y uso de los recursos naturales, así como por los impactos ambientales de las actividades económicas» (INDH, 2015: 5). En el mundo esa cifra asciende a los 2.182 conflictos'.

No obstante las especificidades locales y regionales de cada uno de esos conflictos, lo cierto es que ellos parecen evidenciar la difícil relación entre el desarrollo humano -que apunta a una racionalidad de crecimiento económico ilimitado (Canut de Bon Lagos, 2007: 38) - y la protección del medioambiente que, a su vez, obedece a una lógica de sostenibilidad.

A su vez, el debate más reciente en esta materia da cuenta de la crisis en que se encuentra el propio concepto de desarrollo sostenible, criticado por ser poco atractivo para la opinión pública y demasiado amplio y tardío para resolver los problemas ambientales del planeta, razón por la que aparecen hoy propuestas terminológicas alternativas y de superación, como resiliencia, justicia ambiental o el buen vivir, entre otras (cf. Dernbach y Cheever, 2015).

Acerca de la tensión entre el uso de recursos naturales a raíz del desarrollo de grandes proyectos y su impacto negativo en el medioambiente y en el ejercicio de otros derechos humanos versa la solicitud de opinión consultiva presentada por Colombia ante la Corte Interamericana de Derechos Humanos (CIDH, 2016) en marzo de 2016.

Entre los derechos humanos que se pueden ver vulnerados por el daño ambiental están los derechos a la vida, la integridad física y a la salud, pero también se ven afectadas otras esferas, como la seguridad alimentaria y energética (cf. Moraga, 2009: 118). Por otro lado, el derecho al medioambiente puede colisionar con otros derechos

1. Véase Environmental Justice Atlas, disponible en https://ejatlas.org/. 
humanos que también requieren del uso de recursos naturales (por ejemplo, el derecho a la vivienda en la construcción de proyectos inmobiliarios).

En este contexto surge el debate sobre el contenido que la ley ambiental debiera tener con relación a incentivos al cumplimiento y a la fiscalización, entre otros, con el fin de resguardar bienes jurídicos en disputa (cf. Poklepovic Meersohn, 2010: 176).

La creciente importancia de la temática medioambiental en la arena pública en especial, la tensión entre la protección del medioambiente, derechos humanos y desarrollo- ha contribuido a la aparición de un «activismo ambiental» y de una «democracia ambiental» (Nalegch, 2014: 575-576), reconocidos por el propio derecho internacional ${ }^{2}$. Este activismo se ha traducido en la búsqueda de otros foros e instrumentos jurídicos de protección de alcance internacional, como las cortes regionales de derechos humanos u organismos de derechos humanos de carácter internacional (Stephens, 2009: 54), y la consulta indígena consagrada en el Convenio 169 de la Organización Internacional del Trabajo, OIT (cf. González Carvajal, 2014: 427).

En esta materia, importantes y novedosos planteamientos jurídicos han surgido, como sea considerar a la naturaleza titular de derechos, como lo hizo por primera vez la Constitución del Ecuador de 2008 (Campala, 2013: 10), rompiendo el paradigma clásico, de carácter antropocéntrico (Ávila Santamaría, 2010: 3), del medioambiente como recurso o bien, incluso colectivo, que requiere un uso común sustentable (Lorenzetti, 2008: 7).

Para una reflexión acerca de estos temas, hemos invitados a reconocidos(as) académicos(as) nacionales e internacionales.

\section{Pregunta 1. El derecho al medioambiente y principios rectores}

Una relevante discusión jurídica en torno al derecho al medioambiente está relacionada con su naturaleza jurídica y contenido, que ha llevado, por parte de muchos, a reconocerlo como un derecho humano y fundamental, especificamente el derecho a un medioambiente sano, aunque con matices en el derecho comparado. Asimismo, las constituciones incluyen cláusulas ambientales en el apartado de los principios rectores o bases de la institucionalidad. ¿Cuál es su opinión al respecto? ¿Ambas fórmulas son eficaces y necesarias?

\section{Ramiro Ávila Santamaría}

La relación entre la naturaleza y el ser humano es una de las cuestiones más importantes en este siglo XXI. A lo largo de la historia, los humanos nos hemos relacionado de cuatro formas diferenciadas con la naturaleza. La primera considera a la natura-

2. La Declaración de Río lo contempla en su principio número 10. Véase Stephens (2009: 249). 
leza como un ser superior y hay que venerarla. Una segunda, que lastimosamente es la que predomina, sostiene que somos una especie diferente y superior a la naturaleza y que, por tanto, debemos dominarla. La tercera considera que la naturaleza es necesaria para nuestra sobrevivencia y debemos cuidarla. Finalmente, una cuarta forma reconoce que el ser humano es parte de la naturaleza y hay que respetarla. El derecho se ha adaptado a esas formas. En la primera es la religión confundida con el derecho lo que prima. En la segunda es el derecho civil, que trata a la naturaleza como un objeto y un bien apropiable. La tercera tiene que ver con el derecho humano al medioambiente y con los principios rectores del Estado en política ambiental. En la cuarta, la naturaleza es titular de derechos.

El derecho humano al medioambiente se complementa con los principios rectores de una política pública. El derecho plantea un énfasis en el sujeto titular de los derechos humanos y los principios en la responsabilidad del Estado. Ambos, derechos y principios, ayudan a comprender el contenido y el alcance del derecho al medioambiente. Principios sin derechos permiten mayor discrecionalidad por parte del Estado. Derechos sin principios disminuyen el peso del rol estatal en la protección de la naturaleza. A pesar del reconocimiento del derecho al medioambiente y los principios rectores de una política ambiental, estas regulaciones siguen conviviendo con el derecho civil y el trato a la naturaleza como un bien privado y excluyente. El derecho y los principios han logrado condicionar el derecho de los bienes, estableciendo, por ejemplo, requisitos como la prohibición de contaminación de ciertas actividades económicas, pero siguen subordinados al mercado y al sistema capitalista.

\section{Raúl Campusano Droguett}

El artículo 10 de la Constitución de Ecuador establece que la naturaleza será sujeto de aquellos derechos que le reconozca la Constitución. Más adelante, le reconoce el respeto integral de su existencia, el mantenimiento y regeneración de sus ciclos vitales, estructura, funciones y procesos evolutivos, y el derecho a su restauración. Su equivalente chileno asegura a todas las personas el derecho a vivir en un medioambiente libre de contaminación. En la primera, se le otorga a un ente no humano la calidad de sujeto de derecho, rompiendo con una larga tradición jurídica occidental. En la segunda, se entiende la temática ambiental como un problema de contaminación. Es tanta la distancia entre ambas disposiciones constitucionales que se hace difícil buscar una teoría común sobre el derecho al medioambiente y sus principios rectores. La pregunta, entonces, sobre el derecho al medioambiente desde la perspectiva constitucional requiere opciones previas, no sólo respecto de su ubicación en el texto, sino también sobre la forma en que es entendido en una comunidad dada. $\mathrm{O}$ la forma en que se querría que fuera entendido. Así, una primera definición debiera ser aquella entre antropocentrismo y biocentrismo o ecocentrismo. No parece que 
el derecho constitucional tradicional se haya hecho esta pregunta, pero desde que textos constitucionales reales incorporan principios ecocéntricos, la pregunta deja de ser académica ${ }^{3}$. La opción ecocéntrica tiene profundas y diversas consecuencias que van más allá del tema ambiental y desde ya puede generar una tensión con derechos humanos, al menos en el caso que éstos se entienden de una forma tradicional. Una segunda definición dice relación con la jerarquía que se le otorgue a este derecho y su relación con los demás y con conceptos como el libre emprendimiento, la libertad económica, el derecho al desarrollo, el derecho de propiedad, y otros ${ }^{4}$.

\section{Liliana Galdámez Zelada}

La cuestión ambiental ha sido paulatinamente incorporada en las constituciones contemporáneas bajo diversas fórmulas, como derecho fundamental, como principio rector, cláusula habilitante para la restricción de derechos, como deber de protección (Yarza Fernando, 2012: 35 y ss.) y, también, especialmente en economías en vías de desarrollo o emergentes, se le ha abordado en relación al modelo económico y su necesaria conciliación con la protección del medioambiente y los recursos naturales ${ }^{5}$.

En Latinoamérica se ha desarrollado una práctica extendida que favorece y valora el reconocimiento de derechos fundamentales de contenido ambiental, además de acoger alguna de las otras fórmulas que he enunciado antes. El entusiasmo por el reconocimiento de derechos y la ampliación de los catálogos (Gargarella, 2015) platea varias prevenciones. Desde la experiencia chilena, el derecho fundamental a vivir en un medioambiente libre de contaminación y su tutela a través del recurso de protección, ha sido una herramienta para tratar problemas y afectaciones de derechos desde una perspectiva individual. Una tipología de los recursos de protección en materia ambiental (2009-2016) indica que se refieren a dos grandes bloques de problemas: contaminación y problemas que se produce en entornos rurales, urbanos y naturales, por una parte, y afectación de derechos fundamentales por acción de la industria de la minería y de la energía. Sobre el primer bloque, en la mayoría de los casos se trata de conflictos que se producen a raíz de tensiones entre el derecho a la libre empresa, derecho de propiedad y la protección del medioambiente. El problema es que, cuando se acoge el recurso, no existen mecanismos eficientes de supervisión, esenciales

3. Sobre la tensión entre estos paradigmas, véase Canut de Bon Lagos (2016).

4. Sobre la reflexión bioética entre nosotros, véase Lecaros (2009).

5. No sólo en Latinoamérica, varias constituciones africanas replican esta modalidad. Por ejemplo, el artículo 25 de la Constitución de Somalia: «Medio ambiente 1. Toda persona tiene derecho a un medio ambiente que no sea perjudicial para su salud y bienestar, y a estar protegido contra la contaminación y los materiales nocivos. 2. Toda persona tiene derecho a participar en los recursos naturales del país, al mismo tiempo que se le protege contra la explotación excesiva y perjudicial de estos recursos naturales» (traducción de los editores). 
para garantizar el efectivo e íntegro cumplimiento de los fallos, que muchas veces enfrentan además problemas técnicos para su implementación y cuyo alcance es siempre para el caso concreto. En cuanto a los problemas que se producen por acción de la minería y de la energía, el asunto es más complejo porque lo que se suele recurrir de protección son decisiones adoptadas en el marco del Servicio de Evaluación Ambiental. El recurso de protección se transforma, en este sentido, en una forma para detener por la vía judicial el desarrollo de los proyectos, pero pocas veces los jueces pueden resolver el fondo de los problemas.

La perspectiva sistémica de lo ambiental (esencial para su pleno tratamiento) no se desarrolla desde el litigio caso a caso. Los jueces resuelven problemas puntuales, pero no llegan a abordar los grandes desafíos que supone la protección del entorno, la regulación de la forma en que nos relacionamos con el mundo que nos rodea. La fórmula de los principios, de los compromisos y de las obligaciones de responsabilidad y reparación, me parece, son la clave para construir las reglas para asegurar la supervivencia del mundo que conocemos. El entusiasmo por la consagración de los derechos no debe nublar la mirada a otras fórmulas imprescindibles para la definición de las reglas de lo común.

\section{Jordi Jaria i Manzano}

El reconocimiento del derecho a un medioambiente sano o adecuado se encuadra dentro del patrón de respuesta constitucional a los nuevos problemas sociales que encuentra su raíz en el carácter nuclear de los derechos en la configuración política de la modernidad. En este sentido, desde los años setenta, tanto en el contexto constitucional comparado como en el derecho internacional de los derechos humanos, se ha producido el reconocimiento de algún tipo de derecho subjetivo ambiental en distintos contextos. En cualquier caso, dotar de contenido a un tal derecho no ha sido empresa fácil, lo que ha provocado un cierto rechazo a ese reconocimiento entre la comunidad jurídica.

Sea como sea, el derecho a un medioambiente sano se ha consolidado en el escenario global y cabe entender que proporciona un instrumento para el control de los poderes públicos, lo que no es desdeñable en el contexto de captura del regulador que se produce en la fase actual de evolución de la economía-mundo capitalista. En este sentido, ante la erosión de las instituciones democráticas representativas, el derecho a un medioambiente adecuado, así como los derechos procedimentales que se le asocian —información, participación y acceso a la justicia, de acuerdo con la formulación acuñada en el Convenio de Aarhus-, abre un espacio de posibilidades procesales para el control del poder; en particular, en un escenario donde las instancias estatales tienden a relajar las políticas de protección con el objeto de contentar a los inversores. 
La introducción de normas de principio en relación con el medioambiente responde a una lógica distinta. Es claro que, por una parte, puede haber una cierta pretensión de rebajar la eficacia jurídica de las normas constitucionales - en sentido amplio o material, esto es, no necesariamente recogidas en la constitución formalen relación con la protección del medioambiente, de modo que el legislador tenga un amplio margen de decisión que, en el contexto actual, puede dar lugar a políticas de desprotección. Sin embargo, por otra parte, también es cierto que los principios constitucionales pueden inspirar no solo la acción pública, sino su control. Además, el hecho de que el medioambiente, concebido desde el punto de vista jurídico como configuración normativa del metabolismo social global, sea difícilmente susceptible de individualización en términos de derecho subjetivo, permite pensar que, en realidad, la formulación de la cuestión ambiental en términos de principio fundamental del sistema constitucional - esto es, al nivel del principio democrático o del Estado de derecho- puede ofrecer un camino para la transformación efectiva de la comunidad política en términos de sostenibilidad y justicia. El desarrollo sostenible sería un principio en este sentido, aunque parece cada vez más evidente que presenta carencias muy significativas y que promueve una respuesta puramente gerencial $-y$, en cierto modo, superficial e inadecuada - a la crisis ambiental.

\section{Andrea Lucas Garín}

La incorporación del medioambiente en el catálogo de derechos fundamentales es una decisión del constituyente que ha sido seguida por nuestros países de la mano del constitucionalismo ambiental latinoamericano del que hablaba Raúl Brañes (2001: 12 y ss.). Entiendo que es una decisión trascendental en cuanto asegura que todo el plexo normativo e interpretativo que se ha consolidado en torno a los derechos fundamentales y a la permanente evolución del derecho internacional de los derechos humanos, sea aplicable a este derecho a vivir en un medioambiente libre de contaminación, en terminología de la Constitución de Chile (artículo 19 numeral 8).

Además, la inclusión del medioambiente como principio o base de la institucionalidad en algunas constituciones, de manera expresa y solitaria o sumatoria a la perspectiva de derechos humanos recién mencionada, asegura que la temática sea parte de las políticas públicas de los Estados. Me parece que hay una conexión con la Declaración de Estocolmo del año 1972 en su principio 21, y el desarrollo del derecho internacional ambiental que incorpora el principio de prevención del que deriva la básica obligación para los Estados: tener una política ambiental.

Por todo esto, entiendo que ambas fórmulas constitucionales son necesarias y eficaces. Ellas han permitido una evolución del medioambiente como un derecho fundamental, pero también como parte de la agenda de políticas públicas, ganándose 
un lugar en la mesa de las grandes preocupaciones que las sociedades van atendiendo en su propio imaginario.

Este camino del medioambiente es posible observarlo con claridad en el caso de Chile, que desde la década de los noventa fue ocupándose del medioambiente, de manera institucional y normativa, en un desarrollo de menos a más, contando hoy con un Ministerio del Medio Ambiente que iguala en interés y competencias a los ya tradicionales temas de la agenda pública como justicia y salud.

La conceptualización del medioambiente como derecho humano permite asegurar que sea parte de la fertilización cruzada, que se enriquezca con la jurisprudencia internacional y que en definitiva se fortalezca de cara al derecho nacional.

\section{Pregunta 2. Conflicto de derechos}

En el debate actual una importante y polémica cuestión es la del conflicto de derechos entre, por un lado, la obligación de preservar y conservar la naturaleza y, por otro lado, otros derechos humanos que pueden requerir la utilización inminente de recursos naturales, convirtiendo así el derecho al medioambiente en un límite al ejercicio de otros derechos humanos. Según su visión, ¿qué parámetros jurídicos se deben considerar a la hora de ponderar esos derechos? ¿Puede haber situaciones en que un derecho excluya al otro?

\section{Ramiro Ávila Santamaría}

En el constitucionalismo ecuatoriano y boliviano la tensión entre los derechos de la naturaleza y los derechos humanos es evidente, que en otras circunstancias resulta una tensión entre el derecho al medioambiente y otros derechos humanos. Los métodos de resolución de conflictos de antinomias dependen de la jerarquía entre normas. Si hay tensión entre los derechos de la naturaleza y medioambiente y el derecho civil, predominan los primeros por tener rango constitucional y ser parte del «bloque de constitucionalidad». Si hay conflictos entre normas de igual jerarquía, entonces la ponderación es el método. Los parámetros para ponderar dependerán de la regulación constitucional. Si, por ejemplo, la naturaleza es titular de derechos, entonces habrá un mayor peso abstracto. Si el medioambiente, según la Constitución, se regulará «de conformidad con le ley», entonces el peso abstracto será mucho menor. En cuanto al peso concreto, no se puede resolver en abstracto la ponderación, sino que dependerá de la circunstancias y los hechos del caso ${ }^{6}$.

En Ecuador hubo una interesante discusión, que puede ilustrar la complejidad del problema de la ponderación, cuando se discutió el caso del Parque Nacional Yasuní.

6. Sobre la ponderación, véase Cabonell (2008). 
Por un lado, el Parque es una de las zonas con mayor biodiversidad del hemisferio, habitan ahí dos pueblos indígenas en aislamiento, 165 especies de mamíferos, 110 de anfibios, 72 de reptiles, 630 de aves, 1.130 especies de árboles, miles de especies de invertebrados y es una reserva del pleistoceno (cf. Larrea, 2011: 12). Por otro lado, en el Parque Nacional Yasuní existen reservas probadas de petróleo valoradas en más de 19 mil millones de dólares que, según el discurso estatal, ayudarán a construir escuelas, hospitales y, en suma, al «desarrollo del país». ¿Qué pesa más? ¿Qué derechos prevalecen? En el caso ecuatoriano no hubo ponderación adecuada, el parlamento resolvió a favor de la explotación petrolera en base al argumento de la pobreza de Ecuador sin considerar lo que significaba el daño que se producía en los pueblos aislados y en la biodiversidad. Yo soy de las personas que creen que la explotación de «recursos naturales» es una maldición que ha contribuido a la destrucción de culturas, al debilitamiento de la democracia, a la corrupción, al daño ambiental y que ha traído más males que beneficios (cf. Acosta, 2009). En últimas, un tagaeri (pueblo en aislamiento) vale más, muchísimo más, que un millón de barriles de petróleo. En otras palabras, si tuviera que ponderarlos, la preservación y conservación de la naturaleza sería un valor mayor a su explotación.

\section{Raúl Campusano Droguett}

El tema del conflicto de derechos en materia ambiental ha llevado al desarrollo de la teoría de la justicia ambiental que, como señala Dominique Hervé, «constituye un principio jurídico que debe ser observado por los instrumentos normativos utilizados para regular el acceso, uso y aprovechamiento de los recursos naturales» (2015: 20). El tema de la relación y eventual conflicto de derechos fue tratado en el Informe Brunlandt (1987) que sugiere como camino de salida el concepto de desarrollo sustentable: «satisfacer las necesidades de las generaciones presentes sin comprometer las posibilidades de las del futuro para atender sus propias necesidades». El concepto fue recogido por el juez Christopher Weeramantry en la sentencia de la Corte Internacional de Justicia en el caso Gabcikovo Nagymaros, particularmente en su opinión separada. Y, de allí en adelante, ha sido virtualmente adoptada por todo el mundo. Sin embargo, en los últimos años el concepto ha sido objeto de críticas en el sentido que sería tan amplio y abierto que podría satisfacer cualquier interpretación y, por tanto, carecería de significado y contenido.

El tema de conflicto de derechos se complica con la ampliación y diversificación del concepto de medioambiente. Si se entiende como un tema técnico de contaminación, o como una subdivisión del derecho administrativo interesada en permisos ante la autoridad sectorial, es posible acotar el problema. Pero el derecho ambiental es más, mucho más que contaminación y permisos. Se extiende a la relación del ser humano con su entorno, naturaleza, ecosistemas y seres vivos. Y, posiblemente, sea 
más amplio aún que lo señalado. Y por ello es que la posibilidad de conflicto con otros derechos se active y amplíe significativamente. La sociedad civil organizada ha jugado y juega un rol importante en la definición de las fronteras entre derechos?.

La Constitución chilena establece que la ley podrá establecer restricciones específicas al ejercicio de determinados derechos o libertades para proteger el medioambiente. Así, consagra la idea de conflicto de derechos: el medioambiente sería una restricción, un obstáculo para el ejercicio de otros derechos o libertades. Dejando de lado la posibilidad real de conflicto, no puede dejar de observarse la mirada del constituyente sobre la materia (cf. Guiloff, 2011).

La respuesta a la pregunta sobre qué parámetros jurídicos se deben considerar a la hora de ponderar esos derechos en conflicto dependerá de la idea de sociedad que se tenga. Al final, el tema deriva necesariamente hacia lo filosófico y lo político. ¿Qué tipo de sociedad es aquella en la que quereos vivir? Si se logra responder y acordar una respuesta, es posible saber si hay situaciones en que un derecho excluya al otro.

\section{Liliana Galdámez Zelada}

Para el caso chileno, buena parte de los litigios que ha conocido el Tribunal Constitucional y la jurisdicción ordinaria se relacionan con la tensión entre el derecho fundamental a vivir en un medioambiente libre de contaminación, el derecho de propiedad y la libertad de empresa. La industria minera y la energética han llegado a los tribunales por diversas reclamaciones a raíz de sus efectos en el entorno, la conservación y el acceso a los recursos naturales y la afectación de derechos de las comunidades indígenas.

Sobre el crecimiento económico de Chile, dice la OCDE: «No obstante, este crecimiento sólido se vio acompañado de una tenaz persistencia de la desigualdad de los ingresos y de mayores presiones sobre el medioambiente, sobre todo la contaminación atmosférica, la escasez de agua, la pérdida de hábitats, y la contaminación del agua y el suelo» (Cepal y OCDE, 2016: 3).

Sobre las tensiones entre derechos ${ }^{8}$, en el caso del Tribunal Constitucional es posible apreciar una evolución desde una escasa atención a los derechos de contenido ambiental, hacia un mayor desarrollo y configuración de éstos. La primera etapa se produce en la década de los noventa (sentencias roles 146 de 1992 y 185 de 1994) hasta recientes sentencias (rol 2678-14) que comienzan a desarrollar una mirada más coherente con la doctrina, los criterios de la jurisdicción ordinaria y el conocimiento que se ha desarrollado en torno a lo ambiental, unido a las señales de agotamiento

7. Así, por ejemplo, la ONG Fiscalía del Medio Ambiente (FIMA) que litiga en causas ambientales de interés público.

8. Quisiera referirme a ellos en el marco de los resultados arrojados por el proyecto Fondecyt 11140270. 
que el entorno viene dando desde hace un tiempo. Lo llamativo de la manera en que el Tribunal Constitucional ha abordado la tensión entre derechos, viene del hecho de que la Constitución del 1980 desarrolla una protección fuerte del medioambiente (cf. Galdámez, 2017). Esta protección reforzada se expresa en una cláusula de restricción de derechos por la que el constituyente habilita al legislador para introducir límites a determinados derechos cuando se trata de proteger el medioambiente; además, el artículo 19 número 24 considera dentro de la función social de la propiedad la protección del patrimonio ambiental. Estas normas no han desplegado su fuerza normativa sino hasta recientes sentencias. Lo que quiero decir es que no se trata tanto de la existencia de normas que aseguren, prima facie, la protección del entorno - las que por cierto no descartaría, especialmente cuando se trata de la protección de entornos naturales de especial valor-; de lo que se trata es de una valoración seria y responsable sobre las externalidades que la libertad de empresa genera, no solo para las generaciones presentes, sino también para las futuras.

La técnica jurídica para enfrentar las tensiones entre el medioambiente y otros derechos fundamentales requiere de nuevos dispositivos. Por ejemplo, invocación de criterios de interpretación como el preventivo y precautorio, responsabilidad (de las personas jurídicas y naturales), reparación y una valoración de los derechos de futuras generaciones. Esto implica, además, incorporar la perspectiva de la solidaridad y de lo común.

\section{Jordi Jaria i Manzano}

La tensión entre la preservación del medioambiente y los derechos es consustancial. La crisis ambiental se produce a partir del crecimiento del metabolismo social en el contexto de la economía-mundo capitalista que viene a mostrar el carácter vulnerable y limitado de la base biofísica para la reproducción social. Por su parte, la cultura de los derechos responde al ideal utópico de la modernidad, de manera que define un sujeto abstracto al que se le atribuyen una serie de derechos, que son independientes de la disponibilidad efectiva de los recursos para satisfacerlos.

En este sentido, incluso los derechos liberales originarios implican una posibilidad de deterioro del entorno físico de la reproducción social, que se ve aumentado con el reconocimiento de derechos sociales, claramente vinculados al uso intensivo de los recursos naturales. Es por ello que, en el fondo, la crisis ambiental, en realidad, impugna la misma consideración de los derechos como núcleo fundamental del consenso político - del mismo modo que sucede con la idea del desarrollo, en el contexto del consenso económico-. Por otra parte, el enfoque holístico y a largo plazo que demanda la respuesta social a la crisis ambiental global, en el contexto del inicio de la era del Antropoceno, parece difícilmente conciliable con el carácter fragmentario e inmediato de los derechos. 
Por todo ello, desde la reflexión académica y desde el activismo ambiental, como muestran, por ejemplo, el movimiento de la ecología profunda o el ecofeminismo, se ha propugnado un escenario posderechos, basado en las ideas de cuidado, responsabilidad y precaución, de modo que se superen los déficits de equidad y de sostenibilidad que el manejo actual del metabolismo social global implica. En el contexto constitucional, como he hecho en algún trabajo, podría hablarse de un constitucionalismo de la escasez, por contraposición al constitucionalismo utópico que constituye la matriz hegemónica de la configuración política de la modernidad, o, incluso mejor, de un constitucionalismo de la fragilidad, en el que los derechos humanos continúan ocupando su lugar central en la disciplina de las relaciones interpersonales, pero dejan de hacerlo en la gobernanza del conjunto del sistema Tierra.

Para entender esto correctamente, debe tomarse conciencia de un par de aspectos cruciales. Por una parte, la capacidad de transformación humana del sistema Tierra ha llegado al umbral de que la configuración de éste viene determinada fundamentalmente por la acción de origen antrópico - en esto consiste, fundamentalmente, la narrativa del Antropoceno-, como muestra el fenómeno del cambio climático, lo que exige tomar medidas para sostener la base biofísica de la reproducción social, sin la que los derechos son irrelevantes. Por otra parte, debe tenerse en cuenta la cuestión de las generaciones futuras, de modo que las medidas tomadas para satisfacer derechos de las personas actualmente existentes pueden ir en detrimento de los derechos de las personas por venir. Todo ello, conlleva, a mi juicio, una relativización en sentido estricto de los derechos - esto es, una construcción pragmática, no dogmática, que tenga en cuenta los recursos disponibles y los efectos de la acción humana sobre tales recursos-, así como el avance hacia el reforzamiento de los principios de precaución y responsabilidad como elementos constitucionales basilares de las comunidades políticas del Antropoceno.

\section{Andrea Lucas Garín}

Como tema recurrente en la teoría y en la práctica de los derechos humanos, los conflictos de derechos enfrentan al operador jurídico a una tarea desafiante, que de partida debe ubicar el sentido auténtico de los derechos, y que se revaloriza en especial cuando debe rebalancear los derechos humanos. Anne Peters (2016) indica que es necesario dar lugar a una era de armonización y de integración de los esfuerzos en el derecho internacional, lo que pensamos es aplicable a los derechos humanos.

La gran herramienta que tiene el operador jurídico, a mi parecer, es la interpretación como mecanismo para efectivizar y desplegar el derecho. Esta interpretación exige, desde lo formal, que se armonicen las normas nacionales con las internacionales frente a aquellas que las pongan en conflicto. En nuestros sistemas jurídicos quien realiza esta tarea es centralmente el juez (pero no es el único). 
Desde lo sustancial, el intérprete debe constatar la existencia de estándares relevantes en materia de derecho internacional de los derechos humanos. Aquí las obligaciones contenidas en los tratados internacionales de derechos humanos son la fuente primordial; se agrega lo establecido por los órganos de supervisión del tratado para aquellos favorables al control de convencionalidad ${ }^{9}$. Por último, debe considerar el principio pro homine que señala que debe darse preferencia a la norma y a la interpretación más favorable a los derechos de la persona por sobre la más restrictiva y limitada.

Evitar estos conflictos de derechos es un gran desafío para los Estados. Si son asumidos por las políticas y medidas públicas adecuadas y de manera temprana (por ejemplo, por el área ambiental de manera preventiva), conllevará a una armonización que a la larga implicará un avance en la humanización, entendida como ese proceso inacabado de protección de los individuos ${ }^{10}$, de modo de asegurar la dignidad y la vida humana siempre.

\section{Pregunta 3. Desarrollo del derecho internacional de medioambiente}

En el último año hemos presenciado algunas señales contradictorias en materia ambiental, en especial en cuanto al cambio climático. Por un lado, a nivel internacional, la entrada en vigor el 4 de noviembre de 2016 del Acuerdo de París, y, por otro, a nivel interno, el retroceso en el objetivo de reducir las emisiones de gases de efecto invernadero, por ejemplo, en de Estados Unidos con la firma de la «Orden Ejecutiva de Independencia Energética» por el presidente Donald Trump. ¿Cómo evalúa usted el desarrollo del derecho internacional ambiental como mecanismo que asegure la protección ambiental y la lucha contra el cambio climático a nivel supranacional? En cuanto a los términos en que los Estados contraen obligaciones ambientales en el ámbito internacional, ¿cree que son compromisos claros, capaces de generar obligaciones?

\section{Ramiro Ávila Santamaría}

Una de las sorpresas que tuve cuando hice mi maestría fue descubrir la inmensa regulación existente sobre el derecho internacional ambiental: regulación sobre el aire, el agua, la tierra, los mares, los peces, la flora, la vida silvestre, los humedales, la biodiversidad, los desechos tóxicos... hasta llegar al Acuerdo de París, que tiene

9. El control de convencionalidad cuenta con retractores y promotores. Recomendamos el trabajo de Ferrer Mac-Gregor (2011).

10. Coincidimos con Mangas Martin quien señala que «la humanización del derecho internacional ha conllevado importantes limitaciones a la soberanía de los Estados. El trato de las personas no es un asunto interno de los Estados que pueda escapar a la competencia de las organizaciones internacionales, en particular, de Naciones Unidas» (2014: 194). 
relación con el cambio climático. Dos problemas profundos enfrentan los acuerdos relacionados a la naturaleza y al medioambiente: la exigibilidad y el capitalismo.

La debilidad de todo instrumento internacional está en la estructura de la gobernanza global. Los Estados se someten a los convenios internacionales bajo la premisa de la soberanía nacional. Esto quiere decir que pueden existir Estados que no firmen ni ratifiquen los convenios internacionales, por más importantes y necesarios que sean para el ser humano y para la naturaleza. También quiere decir que, aun en el caso de ratificar los acuerdos, los Estados podrían no cumplir y no existe mecanismo efectivo para garantizar su efectiva vigencia. Aun cuando hay tribunales internacionales y sentencias condenatorias, al final depende de la buena fe y voluntad de los Estados. En relación al cambio climático, el proceder de los Estados Unidos demuestra que a nivel global existe la ley del más fuerte y esto pesa más que el derecho.

El problema de fondo es el sistema capitalista. El capitalismo, entendido como «el sistema social en que predominan de forma hegemónica los procesos de circulación y acumulación de capital a la hora de proporcionar y configurar las bases materiales, sociales e intelectuales de la vida en común» (Harvey, 2014: 24), se basa, entre otras características, en la acumulación infinita, la apropiación de la naturaleza y en la competencia voraz. Un sistema de estas características - las que explican la posición de los Estados Unidos- es absolutamente incompatible con los derechos de la naturaleza o con una protección seria y eficaz del medioambiente. Mientras exista el capitalismo, no solo no se respetará la naturaleza sino que se garantizara la exclusión, la desigualdad y la inequidad (cf. Piketty, 2014; Klein, 2014).

\section{Raúl Campusano Droguett}

El derecho internacional del medioambiente es una disciplina relativamente reciente del derecho y ha tenido desarrollos notables desde sus inicios durante la segunda mitad del siglo XX. Tanto desde la perspectiva organizacional, a través de las cuatro conferencias iniciadas con la de Estocolmo en 1972, y especialmente con la de Río 1992, como con la puesta en vigencia de numerosos tratados multilaterales, como el de cambio climático y el de diversidad biológica, se ha ido configurando una teoría global del derecho ambiental que es alimentada y se expresa en diversos principios, como el de la conservación y preservación, sustentabilidad, desarrollo sustentable, responsabilidad intergeneracional, contaminador pagador, in dubio pro natura, etcétera. De esta forma, lo primero es observar y reconocer el enorme éxito que el derecho internacional del medioambiente ha tenido, primero en generar en la sociedad internacional conocimiento y conciencia de los grandes desafíos que enfrentamos. De la misma forma, también debe observarse la diversidad de materias que abarca, desde la protección de humedales y especies migratorias, a la protección de la capa de ozono y la lucha contra la desertificación. También los esfuerzos de descontami- 
nación de aire, agua y suelos. Y muchos otros temas. Es en este contexto que debiera analizarse el caso del cambio climático, que pareciera ser el mayor desafío que la Humanidad enfrenta actualmente y que tiene relaciones y efectos con virtualmente todas las actividades e intereses humanos ${ }^{11}$.

El Acuerdo de París pareciera ser lo mejor que la sociedad internacional estuvo dispuesta a comprometer en su conjunto, pero es probable que sea un acuerdo insuficiente y ni siquiera está claro si será cumplido por todos, aun en sus propios términos. La tendencia iniciada por la Convención Marco y el Protocolo de Kioto pareció perder energía muy pronto; el Acuerdo de París representa un intento por revertir tal pérdida de energía. Así, si el análisis fuera estrictamente sobre su fuerza vinculante en términos tradicionales, habría que expresar cierta desazón. Sin embargo, el derecho internacional del medioambiente avanza también por caminos paralelos al derecho tradicional, especialmente a través del derecho blando (soft law) y de la creciente conciencia ciudadana sobre la importancia de la acción local y personal (cf. Campusano, 2012). Y esto abre también interrogantes sobre las mejores formas de mitigar los efectos de la contaminación (cf Klein, 2014). Y, por cierto, sobre una comprensión más holística de los avances (cf. Campusano, 2014).

\section{Liliana Galdámez Zelada}

A propósito de este asunto, en el caso de Chile y los compromisos asumidos en la tutela del medioambiente desde la perspectiva del derecho internacional — sin ánimo de ser exhaustiva dado que no existen datos oficiales-, «desde 1925 hasta 2014, Chile ha ratificado 93 tratados, protocolos y enmiendas en materia ambiental [...]. De esos 93 instrumentos, organizados conforme su objeto: sobre protección marítima, se han ratificado veintitrés instrumentos; mientras que dieciséis dicen relación con la conservación de flora y fauna; sobre cambio climático y protección de la capa de ozono se han ratificado once; referidos a la Antártica, ocho; sobre agricultura y alimentación, siete; sobre armas nucleares, siete, y sobre contaminación, seis» (Galdámez, 2017: 137).

La eficacia de estos tratados es relativa, en muchos de ellos se asumen esfuerzos para intentar no contaminar, pero el contenido de las obligaciones es a veces opaco. Así, por ejemplo, a propósito del Acuerdo de París, Chile se comprometió con una «Contribución nacional tentativa de Chile (INDC) para el Acuerdo Climático de París 2015».

Otra cuestión es la extensión e invocación del uso de criterios interpretativos derivados de acuerdos internacionales, no sólo tratados, que han sido importantes, aunque todavía de una manera relativamente marginal, para la invocación de los principios preventivo y precautorio por los jueces. Entre ellos, la «Declaración de la

11. Para múltiples aproximaciones a la pregunta sobre el futuro de la disciplina, véase Leary y Pisupati (2010). 
ONU sobre Medio Humano, Estocolmo, 1972, del 5 al 16 de junio 1972; la Declaración de Río sobre el Medioambiente y el Desarrollo, Cumbre de la Tierra, del 3 al 14 de junio de 1992, Brasil; la Declaración Río +20 'El futuro que queremos', del 20 al 22 de junio de 2012» (Galdámez, 2017: 139).

Estos instrumentos han permitido crear conocimiento en torno a los principios preventivo y precautorio y han contribuido a la difusión de conocimiento sobre los problemas que plantea el entorno y los límites del crecimiento.

\section{Jordi Jaria i Manzano}

El derecho internacional público, en su configuración actual, responde a una serie de fundamentos sobre los que cabe reflexionar para responder a esta pregunta. Señalaré, especialmente, dos: por una parte, la soberanía y la igualdad entre los Estados; y, por otra parte, la separación nítida entre el derecho internacional - que rige las relaciones entre Estados- y el derecho interno - que rige las relaciones en el interior de éstos.

En relación con la primera de las cuestiones, debe notarse, por una parte, que la estructura de la economía-mundo capitalista parte de la existencia de relaciones de intercambio desigual entre el centro y la periferia, lo que genera relaciones de dependencia en lo político que hacen que la igualdad entre los Estados sea puramente formal. Por otra parte, la fase global y financiera del proceso de acumulación capitalista hace que, en este momento, las relaciones de intercambio se produzcan en niveles que trascienden a los Estados, lo que tiene como consecuencia - una entre otras- que estos acaben siendo dependientes para su propia viabilidad de recursos financieros que se generan más allá de sus fronteras.

Todo ello redunda en perjuicio de una soberanía que ya no es capaz de imponerse. Así, en la negociación internacional, los Estados tienden a comportarse como defensores de las empresas y las inversiones con las se encuentran vinculados, de modo que más bien propugnan estrategias destinadas a preservar las posibilidades de desarrollo de la economía-mundo capitalista y acuden, para ello, a soluciones puramente gerenciales. En este contexto, el derecho internacional del medioambiente, construido sobre la idea fundamental del desarrollo sostenible, a partir de la Declaración de Río de Janeiro de 1992, ofrece un escenario de business-as-usual, inadecuado para afrontar los retos planetarios.

Por otra parte, la evolución referida de la economía global hace que las fronteras entre lo interno y lo internacional vayan difuminándose progresivamente, lo que explica construcciones académicas como el constitucionalismo multinivel o la constitucionalización del derecho internacional, que acaban desembocando en la idea de constitucionalismo global como marco conceptual lábil y denso, al mismo tiempo que trasciende los límites de la creación ortodoxa del derecho internacional público a través de la acción de los Estados. 
Pues bien, llegados a este punto, por una parte, resulta difícil que los Estados, en las condiciones en que operan en la actualidad, sean capaces de llegar a formular una política climática coherente y eficaz a través de acuerdos internacionales tradicionales, pero, por otra parte, es concebible la existencia de una diversidad de reacciones ciudadanas, que, entre otras cosas, se articulen al entorno de la litigación climática basada en consideraciones constitucionales, construidas a partir de la idea de un constitucionalismo global. En este sentido, puede suceder que determinadas medidas, como las adoptadas por el Presidente Trump, estén más amenazadas ante los tribunales de justicia que en la arena diplomática. Sin embargo, las deficiencias en relación con el Estado de derecho, en el sentido de la existencia de mecanismos jurisdiccionales eficaces de control del poder, en buena parte de los sistemas institucionales del mundo obligan a una cierta prudencia en este campo.

\section{Andrea Lucas Garín}

Considero que el derecho internacional ambiental es una de las ramas del derecho internacional que más se ha desarrollado en los últimos años, desde la década de los setenta en adelante, desde temas que tradicionalmente eran 'internos' y que de a poco se ha ido ocupando la comunidad internacional, junto con nuevos tópicos que han surgido en base a las informaciones científicas provistas, por ejemplo, por el Grupo Intergubernamental de Expertos sobre el Cambio Climático (IPCC), bajo cuyo alero se ha conformado el Régimen Internacional de Protección del Cambio Climático. Estamos frente a una novel área del derecho internacional que en la cooperación encuentra su herramienta primordial.

Respecto a la lucha contra el cambio climático, hay una preocupación de los Estados por construir una cooperación horizontal entre gobiernos nacionales que se evidencia mucho más al momento de aplicar, por ejemplo, los mecanismos financieros del Protocolo de Kioto ${ }^{12}$.

Los tres instrumentos internacionales dedicados al cambio climático denotan una evolución por mejorar los mecanismos de control y cumplimiento con los que los Estados asumen sus obligaciones ambientales. A mi juicio, son considerables en el ámbito climático, en particular en el Acuerdo de París hay un avance en clarificar los compromisos asumidos por los Estados, que son compromisos a largo plazo que prevén una mayor coordinación entre los compromisos internacionales y las acciones a nivel nacional. Esto puede confirmarse al leer la información brindada por Chile en la Tercera Comunicación Nacional de Chile ante la Convención Marco de las

12. Según Petra Lea Láncos (2010: 280), se establecen además relaciones entre instituciones internacionales, organizaciones de integración económica y gobiernos nacionales, el sector empresarial y la sociedad civil. 
Naciones Unidas sobre Cambio Climático (2016) ${ }^{13}$; se puede apreciar el esfuerzo de transparentar las medidas de mitigación, de adaptación, transferencia de tecnología y financiamiento que está tomando Chile para enfrentar el fenómeno del calentamiento global.

Hay un traslado de enfoque al campo de la cooperación internacional, y en tratados multilaterales se brindan los lineamientos que luego el derecho nacional deberá asegurar, con considerable libertad para decidir qué hacer para cumplir con sus compromisos. En particular, el Acuerdo de París plantea, de manera más expresa, dos procesos consecutivos. El primero es a propósito de la ratificación de los Estados adhiriendo a estos compromisos (ya resuelto por Chile). El segundo conlleva que los Estados deban profundizar en las políticas para enfrentar el fenómeno a nivel nacional. La exitosa entrada en vigencia del Acuerdo de París (en menos de seis meses) no deja de plantear grandes desafíos para su implementación como una verdadera tarea por hacer; todo esto sumado a los avatares de las políticas internas de los Estados ${ }^{14}$.

\section{Pregunta 4. La naturaleza y los animales como titulares de derechos}

La visión tradicional, que es también la dominante, en torno al derecho al medioambiente, es antropocéntrica, siendo el titular de este derecho el ser humano. Sin embargo, han surgido concepciones jurídicas alternativas, que atribuyen a la naturaleza la titularidad de derechos. Es el caso, por ejemplo, de las constituciones de Ecuador de 2008 $y$ de Bolivia de 2009. Por otro lado, también han surgido recientes fallos, por ejemplo, en Argentina y en Italia, que abogan por la concepción del animal como un sujeto de derechos y no como un bien. ¿Cuáles son sus apreciaciones respecto a estos nuevos desarrollos legislativos y jurisprudenciales?

\section{Ramiro Ávila Santamaría}

La única forma de evitar la quinta extinción (cf. Kolbert, 2015), que tiene relación directa con la actividad del ser humano en el planeta, es a través de una forma distinta de relacionarnos con la naturaleza. Los modelos que consideran como objeto a la naturaleza (derecho civil) o que buscan cuidar a la naturaleza para beneficio del ser humano (derechos humanos), no son suficientes. El derecho civil nos ha llevado a la destrucción y el derecho humano permite la explotación de la naturaleza. La Humanidad debe tomar medidas radicales si queremos preservar el planeta como lo

\footnotetext{
13. La Comunicación que fue enviada a finales de 2016 cuenta con 505 páginas y está disponible en http://portal.mma.gob.cl/wp-content/doc/TCN-2016b1.pdf.

14. No debe olvidarse que en otras ocasiones Estados Unidos ha abandonado las negociaciones climáticas. Véase Lucas Garín (2015).
} 
conocimos hasta hace pocos años atrás. En términos jurídicos esa medida requiere considerar a la naturaleza como sujeto de derechos. El problema es que esta forma de concepción requiere dos elementos: otro paradigma epistemológico y otro derecho.

El paradigma epistemológico exige pasar de un modelo antropocéntrico a uno distinto, que puede ser biocéntrico o, mejor aún, sin centro (cf. Acosta y Martínez, 2011). Esto implica salir de la lógica cartesiana, del racionalismo científico, dejar de creer en esa maldición bíblica de que tenemos que dominar a la naturaleza y de que Dios se hizo hombre. Esto exige humildad. El ser humano es animal. El ser humano es naturaleza. Ni superior ni inferior, simplemente es parte de la naturaleza. Para nutrirnos de otro paradigma tenemos que aprender de saberes desperdiciados, como la filosofía de los pueblos indígenas o como la lógica del pensamiento sistémico. Los pueblos indígenas, desde hace mucho tiempo atrás, en general, saben cómo relacionarse con la naturaleza de forma respetuosa (Hidalgo-Capitán, Guillén García y Déleg Guazha, 2014). El pensamiento sistémico valora, en su justa medida, a todos los seres que habitamos en el planeta, como un sistema complejo y vital (Capra y Luisi, 2014).

El derecho se ha construido con el paradigma antropocéntrico. Otro derecho, por oposición al derecho civil, podría ser un derecho «salvaje» (Cullinam, 2011). El derecho salvaje reconoce los ritmos de la naturaleza, nos obliga a retomar nuestra conexión con ella, impone mayores obligaciones a nuestra especie, prohíbe, por ejemplo, la acumulación para ser más rico y nos condiciona para recuperar lo necesario para la vida. El humano puede tomar de la naturaleza lo que necesita para sobrevivir, no para acumular. Esto es, en términos de lo que interpretó un filósofo ecuatoriano, volver al valor de uso (Echeverría, 2010). Todo lo que satisfaga necesidades artificiales (valor de cambio) tiene que ser desestimulado, desechado y prohibido. ¿De qué sirve acumular oro, llenar de cemento la tierra arable, producir más autos, patentar saberes ancestrales, matar animales por diversión o por colección, talar árboles para adornos...? La naturaleza puede vivir sin nosotros, pero nosotros no podemos vivir sin ella (Weisman, 2007).

La humanidad, la tierra, los seres vivos, la vida plena exige otro paradigma y otro derecho.

\section{Raúl Campusano Droguett}

La reflexión sobre si los animales tienen derechos o podrían tener derechos o al menos gozar de algunos derechos es antigua y, sin embargo, en las últimas décadas ha adquirido especial desarrollo, densidad y sofisticación. El tema jurídico se encuentra estrechamente ligado a temas éticos y morales y también espirituales y religiosos. La primera pregunta que antecede al análisis jurídico es sobre si existe un deber ético (y luego jurídico) de los seres humanos respectos de los seres vivos no humanos. Y de la 
mano con esta interrogante, la necesaria reflexión sobre la naturaleza moral y jurídica de tales seres vivos no humanos (cf. Campusano, 2017).

La filosofía griega clásica tendió a negar derechos o valía moral a los animales. El derecho romano clásico recogería estas ideas, consagrando el concepto que los animales no eran ni podían ser sujetos de derecho, sino objetos, cosas. Por su parte, el texto bíblico del Génesis, compartido por varias religiones, señala la primacía del ser humano por sobre el resto de los seres vivos. Un punto de quiebre lo representa Jeremy Bentham, quien argumentó que si los seres humanos eran moralmente dignos de consideración era por su capacidad de placer y dolor. Y observó que los animales también podían sentir dolor (véase el capítulo 17 de su clásico Introduction to the Principles of Morals and Legislation). Peter Singer, con su libro Animal Liberation (1975), es considerado el desencadenante del movimiento de los derechos de los animales. Tom Regan (1985) postula que los animales no humanos son objeto de derechos morales. Así, Regan postula que los animales no humanos son «sujetos-deuna-vida». Un sujeto de una vida es un alguien, no un algo, es un ser al cual su vida le importa incluso si no le importa a nadie más (Campusano, 2017).

Recientemente, ha habido desarrollos jurisprudenciales y constituyentes sobre la materia. El caso de los chimpancés Hércules y Leo ante la Corte Suprema de New York es especialmente interesante por el desarrollo doctrinario aportados a la causa ${ }^{15}$. La Constitución de Ecuador, que otorga derechos a la naturaleza, y la de Bolivia, que avanza en la misma dirección, ameritan una observación atenta en la aplicación y desarrollo de estos derechos (Campusano, 2014b). Todo indica que el derecho del siglo XXI experimentará cambios significativos derivados de los temas indicados.

\section{Liliana Galdámez Zelada}

El reconocimiento de la naturaleza como titular de derechos es una de las respuestas que el derecho puede dar a la crisis ecológica, la pérdida de los hábitats, de biodiversidad, el cambio climático y otros fenómenos asociados. Como comente antes, es visible desde hace unos años la tendencia regional a la ampliación de los catálogos de derechos. Fernando Rey Martínez lo explica así: «Nuestro tiempo se caracteriza por una explosiva fundamentación de los derechos. No sólo porque el catálogo de los derechos fundamentales en textos nacionales e internacionales crezca a velocidad geométrica, sino también porque los tribunales constitucionales americanos [...] tienden a fundamentalizar casi todo» (2012: 13).

15. Corte Suprema del Estado de Nueva York, Matter of Nonhuman Rights Project Inc. (on behalf of Hercules \& Leo) v. Stanley, 29 de julio de 2015. También son interesantes los casos Chimpancé Cecilia, del Tercer Juzgado de Garantías del Estado de Mendoza, del 3 de noviembre de 2016, y Orangután Sandra de la Segunda Sala de la Cámara Federal de Casación Penal de la Ciudad Autónoma de Buenos Aires, del 18 de diciembre de 2014, entre otros. 
Más allá de los problemas técnicos que se asocian a la configuración de derechos para la naturaleza, la pregunta primera es si acaso ésta es la fórmula para asegurar otra forma de convivencia con nuestro entorno. No estoy segura que ésta sea la respuesta adecuada. Me parece que esta fórmula puede encerrar una suerte de populismo ambiental. Más aun en una era que anuncia otros procesos, hasta ahora desconocidos y donde el catálogo de derechos puede ser una respuesta más política, que adecuada:

Más recientemente, sin embargo, se ha sugerido de manera informal que hemos dejado el Holoceno y entrado en una nueva época geológica llamada Antropoceno. Al destacar el papel central de la humanidad en los sistemas geoecológicos, la palabra antropoceno sugiere que la Tierra se está moviendo rápidamente hacia un crítico estado de inestabilidad, en el que los sistemas terrestres se vuelven gradualmente menos predecibles, no estacionarios y menos armoniosos como resultado de la huella humana en la biosfera (Kotze, 2014: 24; traducción de los editores).

A través de los mandatos de protección y principios, creo, es posible desplegar un conjunto de herramientas que permitan asegurar una mejor y más eficaz protección del entorno. Otra cosa es que a través de normas se proteja la diversidad, los paisajes, los glaciares. Esto se consigue mejor con cláusulas generales y no con el establecimiento de derechos. Llegado el momento, la experiencia indica que los jueces tenderán más a proteger los derechos de las personas. No se trata de oponer unos a otros; se trata de propiciar una convivencia respetuosa.

En cuanto los derechos de los animales, ser protegidos no implica que sean titulares de derechos. Su conceptualización como seres sintientes y, por tanto, protegidos contra la violencia y el maltrato, es una fórmula que, creo, satisface los estándares de humanidad que se espera de nuestra sociedad en el siglo XXI. No debemos perder de vista, por otra parte, que en ocasiones determinadas especies se han convertido en una amenaza para la supervivencia de especies nativas (por ejemplo, el drama de los castores en la Tierra del Fuego, o de las cabras en las Islas Galápagos, que afectan el entorno de especies únicas).

Para el futuro, me parece que el derecho debe prepararse para avanzar en nuevas categorías y mecanismos, particularmente para gobernar lo común. Pero sobre todo, y esto es algo que se repite en todos los foros nacionales e internacionales, es el propio modelo el que debe ajustarse a las limitaciones que implica convivir en este planeta. Quizá éste sea el mayor desafío y no es clara todavía la forma en que se concretará el tránsito hacia otro modelo.

\section{Jordi Jaria i Manzano}

A pesar de que, como señalé en la respuesta a la segunda pregunta, existen dudas razonables sobre la idoneidad de los derechos en relación con la respuesta social ade- 
cuada a los retos que plantea la transición hacia el Antropoceno, es lo cierto que los derechos tienen un atractivo político considerable. De manera que, por una parte, en muchos contextos, parece socialmente inaceptable optar por escenarios de menos derechos, y, por otra parte, se impone la idea de formular nuevos problemas y nuevas necesidades sociales en términos de derechos. Esta última tendencia se hace enlazar con la constatación de que los sujetos de derechos y los mismos derechos se han ido ampliando históricamente, de acuerdo con un tipo de razonamiento progresista que forma parte del arsenal cultural de la modernidad y que no es ajeno a la crisis ambiental, que, de hecho, es una crisis civilizatoria que justamente pone en cuestión los patrones modernos.

A partir de aquí se han desarrollado en tiempos recientes dos tradiciones distintas en relación con la ampliación de los sujetos de derechos: por una parte, los derechos de los animales; y, por la otra, los derechos de la naturaleza. Ambas tradiciones responden a consideraciones diferentes y deben ser tratadas por separado. En relación con los derechos de los animales, la cuestión es extender las categorías propias del pensamiento liberal a individuos no humanos, a saber, a los miembros de ciertas especies animales - no todas-. Esta idea enlaza con una preocupación histórica por el bienestar animal que culmina con su formulación en términos de derechos a partir de la obra de Peter Singer Animal Liberation (1975). Esto tiene poco que ver con la crisis ambiental y se formula en términos de dotar de estatus moral a las criaturas capaces de experimentar sufrimiento. Me parece que ésta es una evolución razonable dentro del paradigma de los derechos, que, en todo caso, parece configurarse, sobre todo, como un límite a la crueldad humana, lo que hace perfectamente adecuada la introducción de los derechos aquí, en la medida que estos responden originariamente a la creación de una esfera de intangibilidad ante las agresiones exteriores.

En cualquier caso, los derechos de los animales se encuadran en un patrón moral liberal que es ajeno a las pretensiones holísticas y comunitaristas que se han desarrollado como respuesta radical a la crisis ambiental, cuya relación con los derechos, como ya he dicho, es más bien conflictiva. Esto se pone de manifiesto, a mi juicio, en el caso de los pretendidos derechos de la naturaleza, incorporados por la Constitución de Ecuador en 2008. Teniendo en cuenta el vínculo necesario entre personalidad jurídica y derechos, la consecuencia primera es convertir a la naturaleza en una persona jurídica, lo que, a mi juicio, es totalmente incompatible con su condición de hólos, esto es, como totalidad. En este sentido, considerar la naturaleza como un sujeto en conflicto con otros, que es lo propio de la cultura de los derechos, me parece un planteamiento inadecuado del problema, que más bien debilita que refuerza la tutela jurídica de la Tierra. Por otra parte, los efectos reales de tal reconocimiento han sido más bien escasos, en la medida en que los derechos de la naturaleza no han 
dado lugar a soluciones sustancialmente distintas de las que ofrecería la protección del dominio público o el cumplimiento de la normativa ambiental sectorial ${ }^{16}$.

\section{Andrea Lucas Garín}

El medioambiente, como un escenario que nos engloba, incluye sin duda el bienestar animal como un bien jurídico tutelado por el derecho. En este contexto destaca la sentencia del derecho comparado, originada en Argentina en noviembre de 2016, en que se declara a la chimpancé Cecilia sujeto de derecho no humano ${ }^{17}$. En igual sentido, en Chile la Ley 20.380 de Protección de los Animales, de octubre de 2009, sigue esta tendencia.

Hay distintos tipos de protección que se otorgan a los animales y, detrás de ellas, hay discusiones legales, filosóficas y políticas frente a los avances de la ciencia y las informaciones sobre animales no humanos (véase González Marino, 2016). Cabe señalar que muchas de estas discusiones se están llevando a cabo en países desarrollados con más ahínco.

Pensar en una visión más holística del derecho podrá acercarnos a una relación más equilibrada entre la naturaleza y el hombre, que devendrá en que el sistema jurídico deba plantearse algunas preguntas sobre cómo colaborar con ese equilibrio y posiblemente repensar la relación entre humanos y animales no humanos. Las sociedades elaboran conceptos como el riesgo, y, en el derecho, como el concepto de persona jurídica: las construcciones sociales nuevas podrían incorporar en el futuro algún tipo de «personalidad» al animal. Pareciera que es un tema en construcción.

\section{Referencias}

Acosta, Alberto (2009). La maldición de la abundancia. Quito: Abya Yala. Acosta, Alberto y Esperanza MARTínez (comp.) (2011). La naturaleza con derechos. De la filosofía a la política. Quito: Abya Yala.

Ávila Santamaría, Ramiro (2010). «El derecho de la naturaleza: fundamentos». Repositorio UASB Digital, 3. Disponible en http://bit.ly/2tCegqv.

16. Las limitaciones de espacio me han impedido referenciar en detalle las afirmaciones aquí vertidas. En cualquier caso, consigno una serie de trabajos de mi autoría en los que se encuentra citada una amplia bibliografía en relación con las cuestiones aquí tratadas. En relación con la pregunta 1, véase Jaria Manzano (2014); en relación con la pregunta 2, véase Jaria Manzano (2015); en relación con la pregunta 3, véase Jaria Manzano (2016); y en relación con la pregunta 4, véase Jaria Manzano (2013).

17. La chimpancé estaba alojada en el zoológico de la Provincia de Mendoza y por una acción de habeas corpus presentada por la Asociación de Funcionarios y Abogados por los Derechos de los Animales (AFADA), el Tercer Juzgado de Garantías de Mendoza ordenó el traslado a un santuario de Brasil. Expediente P-72.254/15, «Presentación efectuada por AFADA respecto del chimpancé Cecilia, sujeto no humano», disponible en http://bit.ly/2eGOFpP. 
Brañes, Raúl (2001). Informe sobre el desarrollo del derecho ambiental latinoamericano. México: Programa de Naciones Unidas para el Medioambiente, Oficina Regional para América Latina y el Caribe.

Campala, Fait Simon (2013). «Derechos de la naturaleza: ¿Innovación trascendental, retorica jurídica o proyecto político?» Iuris Dictio, 13 (15): 9-37. Disponible en http://bit.ly/2vzAlTN.

Campusano, Raúl F. (2012). «Desde la certeza de la regla a la diversidad de la práctica: El nuevo derecho internacional del medioambiente». En Ximena Insunza y otros. Actas de las VI Jornadas de Derecho Ambiental. Visión ambiental global: presente y futuro. Santiago: Thomson Reuters.

-. (2014a). «Cambio climático y migraciones: Desafíos para el derecho y las políticas públicas». Revista Actualidad Jurídica, 29: 239-253.

-. (2014b). «El buen vivir y los derechos de la naturaleza en las nuevas constituciones de Bolivia y Ecuador». En Ana Lya Uriarte y otros, Actas de las VII Jornadas de Derecho Ambienta. Recursos Naturales: ¿Sustentabilidad o sobreexplotación? (pp. 105-130). Santiago: Thomson Reuters.

-. (2017). «Sentencia de alto tribunal que abre la posibilidad de reconocer derechos a animales de acuerdo con doctrina de derecho internacional». Revista Actualidad Jurídica, 36.

Canut de Bon Lagos, Alejandro (2007). Desarrollo sustentable y temas afines. Santiago: Consejo Minero.

-. (2016). Ecología y sociedad. Santiago: Ediciones Universidad Finis Terrae.

CABOnell, Miguel (compilador) (2008). El principio de proporcionalidad y la interpretación constitucional. Quito: MJDH.

CaPra, Fritjof y Pier Luigi LuIsI (2014). The systems view of life. A Unifying vision Nueva York: Cambridge.

CIDH, Corte Interamericana de Derechos Humanos (2016). Solicitud de opinión consultiva presentada por la República de Colombia ante la Corte Interamericana de Derechos Humanos de 14 de marzo de 2016. Disponible en http://bit.ly/2w8zxWs.

Cullinan, Cormac (2011). Wild Law. A Manifesto for Earth Justice. Vermont: Chelsea Green Publishing.

Dernbach, John C. y Federico Cheever (2015). «Sustainable development and its discontents». Transnational Environmental Law, 4 (2): 247-287. DOI: 10.1017/ S2047102515000163.

ECheverría, Bolívar (2010). Valor de uso y utopía. México D.F.: Siglo XXI.

Ferrer MAC-Gregor, Eduardo (2011). «Interpretación conforme y control difuso de convencionalidad: El nuevo paradigma para el juez mexicano». Estudios constitucionales, 9(2): 531-622. Disponible en http://bit.ly/2unRloM.

Gargarella, Roberto (2015). La sala de máquinas de la Constitución. Dos siglos de constitucionalismo en América Latina (1810-2010). Buenos Aires: Katz. 
GaldÁmeZ, Liliana (2017). «Medioambiente, Constitución y tratados en Chile». Boletín Mexicano de Derecho Comparado, 40 (148): 113-144. DOI: 10.22201/ iij.24484873e.2017.148.10997

González Carvajal, Paola (2014). «Pueblos indígenas y afectación de recursos naturales». En Jorge Aranda y otros (editores), Actas de las VII Jornadas de Derecho Ambiental: Recursos naturales, ¿sustentabilidad o sobreexplotación? Santiago: Thomson Reuters.

GonzÁlez MARINo, Israel (coord.) (2016). Aproximaciones filosóficas y jurídicas al Derecho Animal. Actas de los Primeros Coloquios del Derecho Animal UCN. Santiago: Ediciones Jurídicas de Santiago.

Guiloff, Matías (2011). «El dilema del artículo 19 núm. 8, inciso segundo». Revista de Derecho Coquimbo, 18 (1): 147-169. DOI: 10.4067/So718-97532011000100oo6

HARVEY, David (2014). Diecisiete contradicciones y el fin del capitalismo. Quito: IAEN. Hervé, Dominique (2015). Justicia ambiental y recursos naturales. Valparaíso: Ediciones Universitarias de Valparaíso.

Hidalgo-Capitán, Antonio Luis, Alejando Guillén García y Nancy Déleg GuaZHA (eds.) (2014). Antología del pensamiento indigenista ecuatoriano sobre Sumak Kawsay. Huelva: CIM/FIUCUHU/Pydlos.

INDH, Instituto Nacional de Derechos Humanos (2015). Mapa de conflictos socioambientales en Chile 2015. Disponible en http://bit.ly/2uPhwOn.

Jaria I MAnzano, Jordi (2013). «Si fuera solo una cuestión de fe... Una crítica sobre el sentido y la utilidad del reconocimiento de derechos a la naturaleza (en la Constitución del Ecuador)». Revista Chilena de Derecho y Ciencia Política, 4 (1): 43-86.

-. (2014). «Derechos y medioambiente». En Albert Noguera Fernández y Adoración Guamán Hernández (dirs.), Lecciones sobre Estado social y derechos sociales (pp. 577-615). Valencia: Tirant lo Blanch.

-. (2015). «El constitucionalismo de la escasez (derechos, justicia y sostenibilidad)». Revista Aranzadi de Derecho Ambiental, 30: 295-349.

-. (2016). «La externalización de costes ambientales en el acceso a los recursos naturales: Marco institucional y distribución inequitativa». Informe núm. 4 del proyecto «Del desarrollo sostenible a la justicia ambiental: Hacia una matriz conceptual para la gobernanza global». Disponible en http://bit.ly/2gXgGtY.

KLEIN, Naomi (2014). This changes everything. Capitalism vs the climate. Nueva York: Penguin Books.

Koтze, Louis J. (2014). «The Anthropocene's Global Environmental Constitutional Moment». Yearbook of International Environmental Law, 25 (1): 24-60. DOI: $10.1093 / \mathrm{yiel} / \mathrm{yvv06}$.

Kolbert, Elizabeth (2015). The Sixth Extinction. An Unnatural History. Nueva York: Picador. 
LÁncos, Petra Lea (2010). «Flexibility and legitimacy. The emissions trading system under the Kyoto Protocol». En Armin von Bogdandy y otros (eds.), The exercise of Public Authority by International Institutions (pp. 271-299). Heidelberg: Springer Beiträge sum ausländischen öffentlichen Recht und Völkerrecht.

Larrea, Carlos (2011). «La iniciativa Yasuní ITT: Una opción factible hacia la equidad y sustentabilidad». En María Cristina y otros (editores), La iniciativa Yasuní ITT desde una perspectiva multicriterial. Quito: PNUD.

Leary, David y Balakrishna Pisupati (eds.) (2010). The future of international environmental law. Tokyo: United Nations University Press.

LeCAros, Juan Alberto (2009). Manual introductorio a la ética medioambiental. Principios éticos y valores para el ciudadano de la sociedad global. Barcelona: Fundación Mapfre.

Lorenzetti, Ricardo Luis (2008). Teoría del derecho ambiental. Buenos Aires: La Ley.

Lucas Garín, Andrea (2015). «Cambio Climático en Estados Unidos: El caso Utility Air Regulatory Group v. EPA». Revista Tribuna Internacional, 4 (8): 283-291. DOI: 10.5354/0719-482X.2015.38556

Mangas Martin, Araceli (2014). Humanización, democracia y Estado de derecho en el ordenamiento internacional. Madrid: Real Academia de Ciencias Morales y Políticas.

Moraga, Pilar (2009). «Evolución de la política nacional energética frente a la regulación del cambio climático». En Pilar Moraga (editora), El nuevo marco legal para el cambio climático. Santiago: Domeyko.

NALEGCH, Constance A. (2014). «Fortalecimiento de la democracia ambiental a través de un instrumento regional». En Jorge Aranda y otros (editores), Actas de las VII jornadas de derecho ambiental: Recursos naturales, ¿sustentabilidad o sobreexplotación? Santiago: Thomson Reuters.

Cepal, Comisión Económica para América Latina y el Caribe, y OCDE, Organización para la Cooperación y el Desarrollo Económicos (2016). Evaluaciones del desempeño ambiental: Chile 2016. Santiago.

Peters, Anne (2016). «The refinement of International Law: from Fragmentation to regimen interaction and politicization». Research Paper 2016-19. Max Planck Institute for Comparative Public Law \& International Law (MPIL). Disponible en https://ssrn.com/abstract $=2823512$.

PiketTy, Thomas (2014). Capital in the Twenty-First Century. Cambridge: The Belknap Press of Harvard University Press.

Poklepovic Meersohn, Iván (2010). «Análisis crítico del sistema de incentivos al cumplimiento ambiental». En Valentina Duran Medina y otros (editores), Derecho ambiental en tiempos de reformas. Actas de las V Jornadas de Derecho Ambiental. Santiago: Legal Publishing. 
Regan, Tom (1985). «The Case for Animal Rights». En Peter Singer (editor), In defense of animals (pp. 13-26). Nueva York: Basil Blackwell.

Rey Martínez, Fernando (2012). Los derechos en Latinoamérica: tendencias judiciales recientes. Madrid: Fundación Internacional y para Iberoamérica de Administración y Políticas Públicas, Editorial Complutense.

Singer, Peter (1975). Animal Liberation: A New Ethics for our Treatment of Animals. Nueva York: Harper Collins.

Stephens, Tim (2009). International Courts and Environmental Protection. Cambridge: Cambridge University Press.

Weisman, Alan (2007). The World without us. Nueva York: Picador.

Yarza Fernando, Simón (2012). Medioambiente y derechos fundamentales. Tribunal Constitucional. Madrid: Centro de Estudios Políticos y Constitucionales.

\section{Sobre los autores}

Ramiro Ávila Santamaría es doctor en sociología jurídica por la Universidad del País Vasco. Master en Derecho por Columbia University (New York). Master en sociología jurídica por la Universidad del País Vasco-Instituto Internacional de Sociología Jurídica. Abogado y licenciado en Ciencia Jurídicas por la Pontificia Universidad Católica del Ecuador (PUCE). Docente de planta del área de Derecho de la Universidad Andina Simón Bolívar-Sede Ecuador, dirige el área de derecho y coordina la Maestría en Derecho Penal. Es autor y editor de varias publicaciones, entre ellas: $E l$ neoconstitucionalismo andino (Quito, 2016), La (in)justicia penal en la democracia constitucional de derechos (Quito, 2013), Neoconstitucionalismo transformador (Quito, 2011), Derechos y garantías. Ensayos críticos (Quito, 2010). Su correo electrónico es ramiro.avila@uasb.edu.ec.

Raúl Campusano Droguett es abogado de la Universidad de Chile. Master en Derecho de la Universidad de Leiden, Países Bajos. Master of Arts en Estudios de la Paz Internacional de la Universidad de Notre Dame, Estados Unidos. Profesor titular y Director Académico del Programa de Magister en Derecho Ambiental y Director de Postgrado de la Facultad de Derecho de la Universidad del Desarrollo. Su correo electrónico es rcampusano@udd.cl.

Liliana Galdámez Zelada es licenciada en ciencias jurídicas y sociales de la Universidad de Chile. Doctora en Derecho por la Universidad de Valladolid. Profesora e investigadora del Centro de Derechos Humanos de la Facultad de Derecho de la Universidad de Chile. Ha desarrollado diversas publicaciones sobre derechos humanos y fundamentales, recepción del derecho internacional de los Derechos Humanos en el ordenamiento interno y es responsable del Fondecyt de iniciación 11140270 sobre derechos, principios y obligaciones ambientales desde una perspectiva consti- 
tucional, cuyos resultados son presentados en este trabajo. Su correo electrónico es lgaldamez@derecho.uchile.cl.

JoRdi JaRIa i MANZano es profesor agregado Serra Húnter de Derecho Constitucional y Ambiental, Universidad Rovira i Virgili (Tarragona, Cataluña, España) e investigador del Centro de Estudios de Derecho Ambiental de Tarragona (CEDAT). Licenciado en Filosofía y Ciencias de la Educación (Universidad de Barcelona, 1994) y en Derecho (Universidad de Barcelona, 1996). Doctor en Derecho (Universidad Rovira i Virgili, 2004). Ha publicado diversos trabajos en relación con las cuestiones planteadas durante las últimas dos décadas. Actualmente, es investigador principal, junto con Susana Borràs Pentinat, en el proyecto «Constitución climática global: gobernanza y derecho en un contexto complejo» (financiado por el Ministerio de Economía y Competitividad, de España).Su correo electrónico es jordi.jaria@urv.cat.

Andrea Lucas Garín es doctora en Derecho y Ciencias Sociales Universidad Nacional de Córdoba, LLM in International Law Universidad de Heidelberg y de Chile; abogada por la Universidad Nacional de Córdoba; investigadora de la Universidad Finis Terrae. Esta entrevista se enmarca en el desarrollo del proyecto Fondecyt de iniciación 2015 núm. 11150382 titulado «Instrumentos comerciales para enfrentar el Cambio Climático en Chile: vínculos con el Sistema Internacional de Comercio» en que se desempeña como investigadora responsable. Su correo electrónico es andrealucasg@hotmail.com. 
